\title{
A Colaboração Profissional em Estudos de Aula na Perspectiva de Professores Participantes
}

\author{
Professional Collaboration in Lesson Studies in the Perspective of \\ Participants Teachers
}

\author{
Adriana Richit ${ }^{*}$ \\ ORCID iD 0000-0003-0778-8198 \\ João Pedro da Ponte** \\ ORCID iD 0000-0001-6203-7616
}

\begin{abstract}
Resumo
O artigo evidencia e discute aspectos da colaboração profissional docente mobilizados no contexto dos estudos de aula, concebidos como uma abordagem de desenvolvimento profissional de natureza colaborativa e reflexiva e centrados na prática letiva. $\mathrm{O}$ estudo centrou-se na realização de entrevistas com sete professores do $1 .^{\circ}$ ao $3 .^{\circ}$ ciclos de Ensino Básico, os quais participaram em três estudos de aula promovidos em um agrupamento de escolas públicas de Lisboa, em 2013-2014, sob a coordenação de uma equipe de investigadores do Instituto de Educação da Universidade de Lisboa. As entrevistas, semiestruturadas, foram realizadas em junho e julho de $2016 \mathrm{e}$ analisadas na perspectiva qualitativa e interpretativa de pesquisa, mediante uma análise de conteúdo dos depoimentos. Os resultados apontam que, no contexto de um estudo de aula, a colaboração docente se concretiza no entrecruzamento de três aspectos principais - a partilha, a cooperação e o apoio pessoal -, manifestando-se, em especial, no planejamento e realização da aula de investigação e nas atividades profissionais cotidianas.
\end{abstract}

Palavras-chave: Colaboração Profissional. Estudos de Aula. Desenvolvimento Profissional de Professores.

\begin{abstract}
This paper analyses teacher collaboration in lesson studies, regarded as a professional development process. We interviewed seven teachers, from the $1^{\text {st }}$ to the $3^{\text {rd }}$ cycle of basic education, who participated in three lesson studies carried out in public schools in Lisbon, in 2013-2014, led by a team of researchers from the Instituto de Educação da Universidade de Lisboa. The interviews were semi-structured and were undertaken in June and July of 2016, being analyzed in the qualitative and interpretative research perspective. The results suggest that in the context of a lesson study, collaboration among teachers takes place in the intersection of three main aspects - sharing, cooperating, and personal stimulus - and show up especially in planning and carrying out the research lesson and in the daily professional activities.
\end{abstract}

Keywords. Professional Collaboration. Lesson Studies. Teacher Professional Development.

\footnotetext{
* Doutorado em Educação Matemática pela Universidade Estadual Paulista (UNESP) de Rio Claro. Pós-doutorado em Didática da Matemática pela Universidade de Lisboa (Ulisboa). Professora, Classe D, nível associado, da Universidade Federal da Fronteira Sul (UFFS), Erechim, Rio Grande do Sul, Brasil. Docente permanente do Programa de Pós-graduação em Educaçao da UFFS. Endereço para correspondência: Avenida Sete de Setembro, 222, Centro, Erechim, Rio Grande do Sul, Brasil. CEP: 99700-300. E-mail: adrianarichit@gmail.com.

** Doutor em Educação pela University of Georgia. Athens, GA, Estados Unidos. Professor catedrático da Universidade de Lisboa, Instituto de Educação, Lisboa, Portugal. Endereço para correspondência: Alameda da Universidade, Lisboa, Portugal. CEP.: 1649-013. E-mail: jpponte@ie.ulisboa.pt.
} 


\section{Introdução}

Discussões e estudos sobre formação de professores têm sido uma constante nas últimas quatro décadas, temática esta que, na atualidade, renova-se e assume relevância em razão da crescente relação entre as questões da qualidade das escolas e os resultados da aprendizagem (ROLDÃO, 2017). Da mesma forma, o movimento de mudanças na sociedade contemporânea impõe mudanças no trabalho e na cultura profissional do professor, colocando-o frente a novos desafios (HARGREAVES, 1993; 1994), dentre os quais promover formas de ensinar que diferem substancialmente da forma como estes profissionais foram ensinados e como aprenderam a ensinar (BORKO; PUTNAN, 1995).

Neste cenário distintos processos de desenvolvimento profissional, com ênfase na modificação das práticas de ensino em sala de aula, têm emergido e assumido relevância, dentre eles os estudos de aula (lesson studies), que consistem em uma abordagem de formação docente centrada na prática letiva e que assume natureza eminentemente colaborativa e reflexiva (PERRY; LEWIS, 2009; PONTE et al., 2014; STIGLER; HIEBERT, 2016).

Os estudos de aula surgiram no Japão no início do século XX, constituindo-se em umas das principais abordagens de formação de professores naquele país (ISODA et al., 2007; STIGLER; HIEBERT, 2016). Posteriormente, os estudos de aula foram implementados nos Estados Unidos, popularizando-se a partir dos anos 1990 e disseminando-se, desde então, por diversos países em todos os continentes (MURATA, 2011; STIGLER; HIEBERT, 2016).

Por suas especificidades, esta abordagem de desenvolvimento profissional tem interessado pesquisadores ao redor do mundo, os quais têm dedicado-se a examiná-la, buscando explicitar suas possibilidades e contribuições para as aprendizagens e o desenvolvimento do professor. Estas pesquisas têm evidenciado importantes aspectos relativos às possibilidades dos estudos de aula para o desenvolvimento docente, tais como melhorar (ou aprofundar) o conhecimento do conteúdo curricular e sobre o modo de ensiná-lo (FUJII, 2016; LEWIS, 2002), promover mudanças na prática de sala de aula (OLSON et al., 2011; PONTE et al., 2014), melhorar a competência do professor no ensino (HUANG et al., 2011), desenvolver colaborativamente investigação sobre as aulas (TAKAHASHI; MCDOUGAL, 2016), bem como desenvolver trabalho colaborativo, partilhando objetivos, discussão de ideias e desenvolvimento conjunto de recursos de ensino (BURROUGHS; LUEBECK, 2010; MURATA, 2011; PUCHNER; TAYLOR, 2006). Dentre os aspectos apontados pelas pesquisas, a colaboração docente tem se destacado, por constituir-se em uma dimensão basilar do desenvolvimento profissional (DAY, 2001) e da cultura de professores em distintos espaços 
educativos e formativos.

A cultura profissional é aqui entendida como um conjunto de crenças, valores, hábitos e formas de agir no interior das comunidades de professores, os quais tiveram de lidar com exigências e constrangimentos semelhantes ao longo de anos que acabam por "conferir sentido, apoio e identidade aos professores e ao seu trabalho" (HARGREAVES, 1998, p. 186). A colaboração, por seu lado, representa um dos princípios cooperativos da associação entre professores em formas administrativamente reguladas e previsíveis (HARGREAVES, 1998). Para além, constitui-se numa proposta de solução organizacional para os problemas contemporâneos da escola, bem como uma solução "flexível para mudanças rápidas e uma maior organização em geral. A colaboração na tomada de decisões e na solução de problemas é uma pedra angular das organizações pós-modernas" (HARGREAVES, 1998, p. 19).

Consideramos assim relevante analisar a colaboração profissional docente em contextos de estudos de aula, como uma forma de identificar e compreender aspectos do trabalho colaborativo inerentes às práticas e à cultura profissional de grupos particulares de professores, aspectos estes que são evidenciados por esta abordagem de desenvolvimento profissional.

Por este viés, o presente exercício analítico recai na discussão sobre a relevância da colaboração, enquanto elemento da cultura profissional, para o desenvolvimento profissional do professor. Para tanto, realizamos uma investigação com professores do Ensino Básico da rede pública de ensino de Lisboa, participantes em estudos de aula, com o objetivo de destacar aspectos intrínsecos à colaboração evidenciados por esta abordagem, olhando exclusivamente sob a perspectiva dos professores participantes e no contexto de dinamização dos estudos de aula.

\section{Cultura profissional e colaboração docente}

A cultura profissional, suas dimensões e implicações nos processos educacionais, tem se constituído em objeto investigativo em diferentes campos de pesquisa em Educação Matemática, sobretudo no campo que circunscreve as investigações com foco na formação de professores. Neste viés, a cultura profissional de professores interessa-nos por entendermos que os elementos que a constituem interferem nas maneiras pelas quais estes ensinam em sala de aula, nas relações profissionais que se estabelecem no interior das instituições educativas e nas práticas profissionais cotidianas (HARGREAVES, 1994).

Nesta perspectiva, as distintas crenças, hábitos, valores, modos de ser e promover o ensino e a aprendizagem em sala de aula, e outros elementos que permeiam o cotidiano 
profissional do professor, constituem as culturas profissionais consolidadas nos espaços educativos. A estas culturas estabelecidas nas escolas denominam-se culturas escolares, concebidas como um "sistema partilhado de representações, valores, crenças e modos de actuar que configuram, constroem e reconstroem a escola" (TEIXEIRA, 1995, p. 78-79).

As culturas de escola circunscrevem outras formas de cultura, como a cultura docente, modificando-se e modificando-a simultaneamente. As culturas docentes, por sua vez, constituem-se nas interações profissionais que se estabelecem no processo educativo e influenciam as culturas escolares. Para Borges (2007, p. 349), a cultura profissional docente nas escolas constitui-se "através da partilha dos hábitos de trabalho que se desenvolvem no estabelecimento escolar, no grupo de professores, na adesão aos valores, às crenças, aos objetivos e princípios definidos, no apoio e no enquadramento social”. E, portanto, a dinâmica de aculturação que permeia a profíssão docente condiciona as estruturas educativas, a forma de organizar os espaços educacionais e o modo como neles são concretizadas as relações profissionais entre professores (GUERRA, 2000).

Para Hargreaves (1998), a cultura docente circunscreve duas importantes dimensões: o conteúdo e a forma. O conteúdo diz respeito as "atitudes substantivas, valores, crenças, hábitos, pressupostos e formas assumidas de fazer as coisas", partilhados "no seio de um grupo particular de professores" (HARGREAVES, 1998, p. 186). A forma tem a ver com os "padrões característicos de relacionamento e nas formas de associação entre os membros destas culturas" (HARGREAVES, 1998, p. 186). Em face destas dimensões, o autor define quatro tipologias de culturas docentes, sendo uma delas a colaboração' ${ }^{1}$.

A colaboração, conforme Hargreaves (1998), caracteriza a interação em seu sentido mais estrito, que se estabelece entre os professores, à medida que estão envolvidos em uma atividade comum, partilhando objetivos também comuns. A este respeito Borges (2007, p.370371) acrescenta que uma "cultura de colaboração profissional é aquela em que tudo, o bom, o mau, a incerteza, a certeza se partilham, são discutidos, em que se procura o apoio e a ajuda necessários para aprender".

Além dos aspectos da colaboração acima abordados, Fullan (1995) diz que as pesquisas sobre as culturas colaborativas da escola mostram que as aprendizagens do professor são constituídas, especialmente, nas interações cotidianas entre colegas que compartilham a preocupação com a aprendizagem contínua. Neste sentido, as formas de partilha concretizamse na prática profissional e tornam-se significativas para a vida e o trabalho docente, pois a

\footnotetext{
${ }^{1}$ Os outros três tipos de culturas profissionais destacados por Hargreaves são o individualismo, a colegialidade artificial e a balcanização.
} 
confiança que emerge da "partilha e do apoio colegial condiz a uma maior disponibilidade para fazer experiências e para correr riscos e, com estes, a um empenhamento dos docentes num aperfeiçoamento contínuo, enquanto parte integrante das suas obrigações profissionais" (HARGREAVES, 1998, p. 209).

Além da partilha, a colaboração envolve outros elementos, tais como a cooperação, a confiança, a ajuda mútua, o diálogo, a negociação, a superação de hierarquias, etc. Segundo Boavida e Ponte (2002), em contextos de colaboração os professores trabalham conjunta e cooperativamente numa base de igualdade em que a confiança e a ajuda mútua os levam a alcançar objetivos em que todos se beneficiam. Complementam que a colaboração pode se desenvolver entre pares, no seio de grupos que trabalham em torno de um mesmo projeto, ou entre atores que assumem estatutos e papeis diferenciados, como, por exemplo, entre professores e alunos, professores e investigadores. E a diversificação na constituição de um grupo colaborativo decorre dos objetivos do trabalho a ser realizado. Concluem que, apesar dos desafios que podem surgir nestes grupos, a diversidade de pontos de vista pode favorecer compreensões amplas e profundas sobre uma mesma realidade (BOAVIDA; PONTE, 2002).

Nesta perspectiva, a distinção entre cooperação e colaboração, de acordo com Day (1999), prende-se ao modo como as relações pessoais e as relações de poder se concretizam, uma vez que, em grupos puramente cooperativos, as relações de poder e os papéis dos participantes não são questionados, enquanto que a relação colaborativa pressupõe negociação cuidadosa, tomada conjunta de decisões, comunicação efetiva e aprendizagem mútua num empreendimento que se foca na promoção do diálogo profissional. Portanto, a cooperação que ocorre em um grupo colaborativo é permeada por outros elementos, especialmente o apoio, o diálogo e a negociação, que a tornam um princípio da colaboração.

A este respeito, Goulet e Aubichon (1997) acrescentam que o primeiro passo para a colaboração é a confiança, a qual se desenvolve em um contexto de respeito e cuidado, perpassando os níveis pessoal e profissional. A confiança é fundamental para que os membros de um grupo sintam-se a vontade para expor suas ideias e questionamentos, assim como para questionar as ideias, valores e ações dos outros, respeitando-os e valorizando-os, ao mesmo tempo que o seu trabalho e os seus valores são respeitados e valorizados. Portanto, sem confiança não há colaboração (BOAVIDA; PONTE, 2002).

Além disso, o diálogo é também fundamental para a concretização da colaboração. Sobre isso, Olson (1997) pontua que uma relação de colaboração solicita a aceitação da voz pessoal, decorrente da experiência, e a consciência de que nenhuma ideia é definitiva, pois na medida em que uma voz se entrelaça a outras vozes, a compreensão enriquece-se e a 
conversação torna-se mais informada. O diálogo constitui-se, portanto, em instrumento de confronto de ideias e de construção de novas compreensões (OLSON, 1997).

Para além, a colaboração pressupõe negociação, pois, em um grupo colaborativo, são negociados objetivos, modos de trabalho e de relacionamento, prioridades e significados de conceitos fundamentais (BOAVIDA; PONTE, 2002). Para Christiansen, Goulet, Krentz e Maeers (1997, p. 285), “a chave para uma colaboração bem sucedida é uma negociação aberta da partilha de poder e expectativas relativamente ao papel de cada um dos participantes, à medida que um projeto se desenvolve".

A colaboração pressupõe também, de acordo com Boavida e Ponte (2002), adesão voluntária e uma relação próxima entre os participantes. Nesta direção, Fialho e Sarroeira (2012) esclarecem que a colaboração pode dar-se de forma espontânea, voluntária e informal entre os membros de determinado grupo social, baseando-se na partilha, confiança e apoio mútuo e permeando atividades distintas, tais como a partilha de materiais, o planejamento de aulas e demais atividades profissionais, definição de critérios e instrumentos de avaliação, bem como o diálogo sobre os resultados alcançados nas práticas de sala de aula.

Relativamente à constituição e funcionamento de um grupo colaborativo, Ponte (2014, p. 368) acrescenta que

A colaboração pode prosseguir propósitos diversos e assumir formas diferenciadas.
Envolve assumir objetivos comuns e uma divisão de trabalho racional, num quadro
de confiança pessoal, onde todos têm algo a ensinar e a aprender com os outros. Desse
modo, a colaboração não constitui um valor moral, que deve ser prosseguido de uma
dada maneira, mas, pelo contrário, é encarada como uma solução encontrada por um
grupo para resolver problemas comuns, que seriam difíceis de resolver de forma
puramente individual.

Ao examinar a natureza da colaboração que se concretiza em processos formativos realizados em Portugal, Ponte (2014) destaca que a colaboração emerge, muitas vezes, de um desafio lançado por um investigador, que promove a constituição de um grupo colaborativo mais alargado, o qual envolve membros com diferentes tipos de saberes e atividades profissionais no estudo de um problema complexo. Em outros casos, surge como uma prática espontânea e natural dos professores, em situações específicas, tais como, por exemplo, quando enfrentam uma situação nova, como a introdução de um novo programa curricular.

A colaboração docente, portanto, concretiza-se à medida que os integrantes do grupo se comprometem a "fornecer apoio mútuo, oferecer feedback construtivo, desenvolver objetivos comuns e estabelecer limites que apresentem desafios (mas que sejam, ao mesmo tempo, realistas) a respeito daquilo que pode ser razoavelmente realizado" (HARGREAVES, 1998, p. 19). Neste viés, a colaboração entre professores que se consolida no contexto da escola 
constitui-se em uma importante dimensão do desenvolvimento profissional docente (HARGREAVES, 1998; LIMA, 2003).

Em face a estas discussões e estudos, um importante conceito está subjacente: o desenvolvimento profissional docente, que diz respeito ao desenvolvimento da competência profissional do professor em relação às práticas letivas e não letivas, bem como na sua autonomia nas práticas de ensino em sala de aula e como elemento da organização escolar (PONTE, 1998).

Nesta perspectiva, o desenvolvimento profissional circunscreve não apenas o que se passa em sala de aula. Reflete também as relações que o professor estabelece no seu exterior, na partilha de pensamentos e competências com os colegas, melhorando a prestação da escola no sucesso dos alunos (SECO, 2009). Portanto, desenvolvimento profissional é a soma total das aprendizagens formais e informais perseguidas e experienciadas em um ambiente de aprendizagem envolvente sob condições de complexidade e mudança dinâmica (FULLAN, 1995; PONTE, 2014).

Em síntese, o desenvolvimento profissional docente concretiza-se mediante as aprendizagens profissionais, promovidas de forma dinâmica e contínua, nos níveis pessoal e social, a partir das interações entre profissionais de um grupo particular em que ideias são transformadas e experiências reinterpretadas (FLORES, 2004). Em outras palavras, a colaboração é fundamental para o desenvolvimento profissional dos professores porque favorece as aprendizagens profissionais, embasando, assim, a concretização de mudanças nas escolas (DAY, 2001).

\section{Estudos de aula}

O estudo de aula caracteriza uma abordagem de desenvolvimento profissional de professores centrada na colaboração e na reflexão (MURATA, 2011). Esta abordagem envolve pequenos grupos de professores, que trabalham colaborativamente em torno das seguintes etapas: definição de objetivos de ensino a partir das dificuldades de aprendizagem dos alunos; planejamento de uma aula para uma turma de alunos (a aula de investigação); desenvolvimento desta aula complementada pela observação por uma equipe de professores e/ou pesquisadores; reflexão sobre as ações dos alunos registradas pela equipe durante a aula 
investigação; e seguimento ${ }^{2}$ (PONTE et al., 2014). No estudo de aula o professor tem a possibilidade de refletir sobre a prática profissional em um contexto de colaboração.

Por suas peculiaridades, os estudos de aula propiciam oportunidades formativas, por meio das quais o professor pode aprofundar conhecimentos e refletir sobre a necessidade e pertinência de mudanças na prática profissional, aprofundar os conhecimentos matemáticos sobre conceitos diversos e sobre o lugar desses conceitos no currículo, analisar os diferentes tipos de tarefa a propor aos alunos e as suas consequências na aprendizagem, bem como debruçar-se sobre diversos modos de organização da aula e diferentes formas de conduzi-la, tanto nos momentos de trabalho a pares e pequenos grupos, como nos momentos de trabalho coletivo (PONTE et al., 2014).

Olson, White e Sparrow (2011) consideram que os estudos de aula fornecem uma sólida estrutura para a aprendizagem profissional do professor, que pode trazer resultados muito positivos se desenvolvidos em ambientes escolares. De acordo com esses autores, as vivências do professor em um estudo de aula podem favorecer o desenvolvimento profissional, pois promovem mudanças pedagógicas de duas naturezas: encorajando os professores a refletirem criticamente sobre suas práticas de sala de aula, o que os leva a desenvolver uma prática investigativa; e propiciando um contexto em que discutem novas perspectivas com os colegas, o que leva a transformações nas práticas de sala de aula.

Para além disso, Burroughs e Luebeck (2010) ressaltam que os estudos de aula permitem aos professores, em suas práticas profissionais, desenvolverem trabalho colaborativo, o qual caracteriza-se pela partilha de objetivos, pela discussão de ideias e pelo desenvolvimento conjunto de recursos de ensino. Em outras palavras, os estudos de aula, pela sua dinâmica muito peculiar, em que a colaboração constitui um contexto para favorecer os processos de comunicação entre os participantes e a reflexão sobre a prática profissional, têm sido considerados como importante forma de promover o desenvolvimento profissional de professores (PONTE et al., 2016; STIGLER; HIEBERT, 2016).

Nesta perspectiva, os estudos de aula colocam-se como uma importante via de introdução de mudanças em Educação, pois viabilizam, segundo Hargreaves (1998), a constituição de culturas de ensino no interior de pequenas comunidades profissionais, as quais podem trabalhar conjuntamente e de forma colaborativa.

\section{Metodologia do estudo}

\footnotetext{
${ }^{2}$ Seguimento é a etapa que caracteriza a repetição de todo o processo com vistas a desenvolver a aula de investigação com outra turma de alunos. Nos estudos de aula analisados neste texto não houve seguimento.
} 
A pesquisa segue a abordagem qualitativa e interpretativa (ERICKSON, 1986), baseada em uma análise de conteúdo (BARDIN, 1977), a partir da qual buscamos evidenciar, na perspectiva dos professores participantes, aspectos relacionados à concretização da colaboração docente no contexto de estudos de aula, guiando-nos pela seguinte questão investigativa: Quais aspectos da cultura profissional de professores que ensinam Matemática no Ensino Básico são promovidos em estudos de aula segundo a perspectiva dos participantes?

A investigação foi desenvolvida mediante a realização de entrevistas semiestruturadas com professores do Ensino Básico, do $1 .^{\circ}$ ao $3 .^{\circ}$ ciclo, de escolas públicas de Lisboa, os quais participaram voluntariamente em três estudos de aula no decorrer do ano letivo 2013-2014 (ano letivo em Portugal). Cada estudo de aula envolveu apenas um grupo de professores, de acordo com o ciclo de ensino em que atuavam $\left(\mathrm{EA}^{3} 1\right.$ : professores do $1 .^{\circ}$ ciclo; EA 2 : professores do $2 .^{\circ}$ ciclo; EA 3: professores do $3 .^{\circ}$ ciclo), constituindo-se de doze sessões, de aproximadamente duas horas cada, sob a coordenação de uma equipe de professores investigadores do Instituto de Educação da Universidade de Lisboa.

Todos os encontros de cada estudo de aula ${ }^{4}$ foram realizados em escolas em que os professores lecionavam, seguindo criteriosamente a dinâmica de desenvolvimento que caracteriza esta abordagem e centrando-se em estudos curriculares e teóricos sobre o ensino da Matemática, aprofundamento de tópicos da Matemática a ensinar e sobre o estudo de aula.

As entrevistas, organizadas em oito questões que focavam a dinâmica de desenvolvimento do estudo de aula e aspectos da colaboração profissional evidenciados em suas distintas etapas, foram realizadas em junho e julho de 2016, no âmbito de uma pesquisa de pós-doutorado. O convite para participar das entrevistas foi dirigido a todos os professores que participaram dos referidos estudos de aula (total de doze professores), dos quais sete aceitaram participar voluntariamente da pesquisa.

Os sete professores que participaram da pesquisa são Idalina, Irene e Marta, do $1 .^{\circ}$ ciclo (1. ${ }^{\circ}$ ao $4 .^{\circ}$ ano); Luísa, do $2 .^{\circ}$ ciclo $\left(5 .^{\circ}\right.$ e $6 .^{\circ}$ anos); Alda, Idália e José, do $3 .^{\circ}$ ciclo $\left(7 .^{\circ}\right.$ ao $9 .^{\circ}$ ano) (nomes fictícios). Estes professores pertencem a um agrupamento escolar de Lisboa e possuem experiência profissional entre 6 e 15 anos de docência.

A escolha por este grupo justifica-se pelo fato de terem participado de estudos de aula realizados à época em que um novo programa curricular de Matemática estava sendo implementado no Ensino Básico em Portugal (2013-2014), processo esse que solicitou dos

\footnotetext{
${ }^{3}$ EA 1 - Estudo de aula 1; EA 2 - Estudo de aula 2, EA 3 - Estudo de aula 3.

${ }^{4} \mathrm{O}$ detalhamento destes estudos de aula e os seus resultados são discutidos nos trabalhos de Ponte et al. (2014), Ponte et al. (2015) e Ponte et al. (2016), entre outros trabalhos produzidos.
} 
professores a mobilização e o desenvolvimento de conhecimentos profissionais distintos na reorganização dos conteúdos curriculares e das práticas de sala de aula. Além disso, focamos nestes grupos de professores por atuarem nos três ciclos do Ensino Básico, completando uma etapa do ensino escolar, permitindo-nos compreender aspectos da cultura profissional evidenciados em estudos de aula que envolveram professores de uma mesma realidade profissional (todos pertenciam a um mesmo agrupamento escolar) e um nível de ensino escolar completo.

As entrevistas foram gravadas em áudio, transcritas e textualizadas, e a seguir foram enviadas aos professores para validação do material empírico constituído. Mediante a leitura deste material, buscamos destacar elementos basilares da colaboração profissional verbalizados nos depoimentos, estabelecendo assim as evidências empíricas interpretadas e discutidas nas seções seguintes deste texto.

Tais evidências foram estabelecidas na fase de identificação das unidades de contexto, segundo Bardin (1977), em que buscamos nos depoimentos referência a aspectos da colaboração profisssional evidenciados em face a dinâmica do estudo de aula. Em seguida agrupamos os excertos, segundo a convergência entre eles, em unidades temáticas, que acabaram por constituir as categorias de análise (BARDIN, 1977) apresentadas e discutidas neste texto. A análise baseou-se exclusivamente nos depoimentos dos professores, pois buscamos explicitar os aspectos da colaboração favorecidos pela dinâmica dos estudos de aula, os quais foram evidenciados e valorizados pelos professores participantes.

A partir da análise realizada foram destacados aspectos intrínsecos à colaboração profissional, nomeadamente a partilha, a cooperação e o apoio pessoal, os quais constituem as categorias de análise deste texto. Estes aspectos perpassaram os processos de planejamento da aula de investigação seguido da sua lecionação, bem como a organização e realização das atividades profissionais cotidianas, as quais são influenciadas pelas condições de trabalho do professor, em constante modificação devido a diversos fatores internos e externos à profissão.

\section{Aspectos da colaboração profissional manifestados pelos professores participantes}

\subsection{Partilha}

Relativamente a este aspecto, os professores evidenciaram que a dinâmica de desenvolvimento de cada uma das etapas do estudo de aula, especialmente o planejamento da aula de investigação, seguido da sua concretização, permitiu-lhes fortalecer a partilha. 
Afirmaram que as atividades promovidas em face aos estudos de aula intensificaram a partilha entre colegas e que essa partilha passou a ser melhor, abrangendo recursos didáticos para o ensino, experiências de sala de aula, preocupações profissionais e, também, objetivos relativos ao ensino de tópicos curriculares específicos.

Para o grupo de professoras do $10^{\circ}$ ciclo, no estudo de aula partilharam não apenas recursos, mas também o desafio de prepararem-se para ensinar novos conteúdos em sala de aula, nomeadamente o tópico Números Racionais. Ao refletir sobre o tópico curricular da Matemática escolhido para abordar no estudo de aula, Idalina diz que:

Era a primeira vez que nós tínhamos de implementar os números racionais, que foi o conteúdo que escolhemos trabalhar no estudo de aula, e tínhamos de implementar isto com os alunos. E tínhamos noção de que é muito complicado [...], o mais complexo do programa do terceiro ano $e$, portanto, escolhemos trabalhar o conteúdo programático que nós queríamos trabalhar com os miúdos. [E uma] coisa que marcou imenso naquela formação foi a colaboração que havia entre nós. Não era só a partilha que estava melhor. Nos preocupávamos em saber como cada uma tinha feito esta ou aquela tarefa com os miúdos, como eles tinham reagido, que dificuldades sentiram. E depois, quando nos sentamos para partilhar as experiências, pensávamos em maneiras de auxiliar os alunos, nas dificuldades deles. E não escondiamos nada. Havia ali sempre uma preocupação, um desafio que, com as pares, buscávamos superar (Gravação de áudio de Idalina, 1. ${ }^{\circ}$ ciclo, junho de 2016).

Idalina enfatiza o desafio que lhes foi colocado pelo novo programa de Matemática, que levou-as a escolher este tópico, e acrescenta que o estudo de aula oportunizou-lhes partilhar experiências de natureza pedagógica, especificamente sobre modos de promover o ensino de tópicos matemáticos no $1 .^{\circ}$ ciclo, contemplando as necessidades dos alunos e as dificuldades que eles poderiam vir a encontrar na aprendizagem de tais tópicos. $\mathrm{O}$ depoimento de Irene reafirma a intensificação das formas de partilha entre o grupo e destaca a dimensão dialógica desta partilha, à medida que o grupo reunia-se para conversar sobre aquilo que pretendiam desenvolver com os alunos e sobre como o fariam.

[A] experiência que tive nessa formação consolidou e aumentou a nossa forma de partilharmos umas com as outras [...]. Nós já partilhávamos, mas tudo de uma forma, partilhamos, partilhávamos de uma forma informal. Sentarmo-nos em torno de uma mesa e estudarmos um exercício para aplicar aos alunos, isso nós não fazemos. Mas, conversamos e trocamos experiências, não só, por exemplo, de qualquer conteúdo que vamos aplicar aos alunos, não é, isto foi diferente. E conversamos, para abordar esse conteúdo, o que tu achas? Vamos seguir a este caminho ou seguir algum outro? Já fizeste? Vais fazer? Como é que vamos fazer? Acho que podemos fazer no mesmo dia? Como é que? Como é que tu achas que vamos abordar isso perante a turma? E depois, por outro lado, também conversamos muito sobre a maneira como eles reagiram, como eles portaram se à atividade (Gravação de áudio de Irene, 1. ${ }^{\circ}$ ciclo, junho de 2016).

Merece destaque no depoimento de Irene, também, a forma partilhada com que buscavam aprofundar este tópico da Matemática, estudando e discutindo as tarefas que apresentariam aos alunos, aspecto este que estreitou as relações no grupo. Este aspecto é 
ressaltado por Marta, para a qual o diálogo e a cumplicidade que havia entre elas promoveu o crescimento do grupo e a superação de desafios relativos ao ensino dos Números Racionais.

[No estudo de aula tudo era] muito discutido. Dialogamos muito, conversamos muito. E isso também nos deixou mais envolvidas, porque aprendemos a ouvir uns aos outros, aprender com o outro, com o ponto de vista do outro, porque nós estamos, estamos a crescer quando ouvimos as outras pessoas e o que nós temos a aprender com elas, com sua experiência (Gravação de áudio de Marta, $1 .^{\circ}$ ciclo, junho de 2016).

Em síntese, para este grupo de professoras, a pressão exercida pela implementação de um novo programa de Matemática em Portugal, à altura, colocou-as diante do desafio de se preparem para ensinar novos conteúdos curriculares nos níveis em que atuavam, levou-as a partilharem esta angústia no âmbito do estudo de aula, a enfrentarem os desafios advindos dessa mudança e a sentirem a necessidade de buscar esta preparação. O assumir deste objetivo comum também contribuiu para consolidar a colaboração entre as colegas do grupo, à medida que valorizavam a partilha de recursos, objetivos, experiência e o trabalho em grupo, concretizado intensa e colaborativamente para alcançar este propósito. Portanto, no nível do planejamento da aula de investigação e da sua lecionação, os professores destacam que todo o processo foi desenvolvido mediante um longo e minucioso trabalho em conjunto, marcado pela partilha, reflexão e diálogo.

Também para os professores dos $2 .^{\circ}$ e $3 .^{\circ}$ ciclos a experiência no estudo de aula levouos a partilharem materiais didáticos, preocupações profissionais, objetivos relativos à aprendizagem dos alunos e impressões sobre aquilo que cada um tinha realizado no âmbito das atividades do estudo de aula, assim como fortaleceu o diálogo:

No estudo d'aula foi tudo diferente, foi mais intenso. Nos aproximamos mais, conversamos mais, ajudamo-nos mais porque tínhamos a mesma preocupação, que era pensar nas dificuldades e na aprendizagem dos alunos [...]. E também levávamos para o grupo o que cada um tinha encontrado, uma tarefa interessante, um material e, pronto. Discutíamos mais e cada um falava sobre o que tinha percebido (Gravação de áudio de Luísa, 2. ${ }^{\circ}$ ciclo, junho de 2016).

Luísa destaca a preocupação partilhada pelo grupo com a aprendizagem dos alunos e com as dificuldades deles em relação aos tópicos abordados e, à medida que passaram a encontrar-se mais, a conversar mais, a ajudar-se mais, acabaram por ficar mais próximos. Estes aspectos marcaram as interações profissionais que se estabeleceram nos estudos de aula.

Alda ressalta, além da partilha de objetivos de ensino e de tarefas profissionais, a possibilidade de dirimir o isolamento que marca o trabalho pedagógico docente, à medida que grupos de professores têm a possibilidade de constituir-se como coletivos profissionais.

E acho que éramos construtivos, pronto. E estávamos ali todos a trabalhar para o mesmo fim. E é interessante porque o nosso trabalho, eu acho que é, talvez, outra lacuna que há às vezes no nosso trabalho de professores, é que é um trabalho que não vê, que é mais isolado do que 
deveria. Estamos muito isolados, cada um, cada professor a pensar nas suas aulas, no que vai fazer. Eu acho que isso tudo depois vai parar na mesma coisa, no tempo, no tempo que nós temos, porque é importante, às vezes, haver momentos para os professores conversarem (Gravação de áudio de Alda, 3. ${ }^{\circ}$ ciclo, julho de 2016).

Portanto, face a este nível de partilha, a colaboração que houve no grupo teve influência nas atividades concretizadas no estudo de aula, estendendo-se para algumas atividades profissionais, tais como no planejamento de aulas e na organização das demais atividades escolares, práticas estas que passaram a ser realizadas de uma forma partilhada, dialogada e colaborativa, à medida que cada professor se responsabilizava por uma parte do trabalho. E, ainda, a boa relação que havia nos grupos e a intensificação da comunicação entre os pares, que se consolidou e intensificou a partir do estudo de aula, influenciaram as formas de interação entre eles e as relações profissionais e pessoais, prolongando-se para algumas práticas cotidianas, especialmente sobre o ensino em sala de aula, visto que passaram partilhar os conteúdos e as estratégias de ensino.

Em síntese, a partilha que houve nas etapas de planejamento e concretização da aula de investigação, que acabou por se alargar para outras atividades cotidianas, tais como a gestão das rotinas escolares em face aos desafios que surgiam com o novo Programa, consolidou a colaboração entre eles, contribuindo para o seu desenvolvimento profissional.

\subsection{Cooperação}

No que diz respeito à cooperação, outro importante aspecto da colaboração profissional docente, a análise evidencia que as diferentes atividades ao longo dos estudos de aula, particularmente as etapas de planejamento e realização da aula de investigação, foram desenvolvidas de forma cooperativa nos grupos, permeadas pela negociação, confiança e respeito às possibilidades de tempo de cada um. As professoras do $1 .^{\circ}$ ciclo afirmam que a cooperação constituiu-se em um importante aspecto da colaboração naquele grupo, oportunizando uma experiência de formação docente intensa, construtiva e positiva.

Penso que uma das coisas que havia naquela formação, uma coisa que havia entre nós, no nosso grupo do $1 .^{\circ}$ ciclo, era a confiança, o apoio entre nós [...]. E o trabalho em grupo, com as pares, foi também intenso e, portanto, os encontros da formação eram imenso construtivos, imenso positivos (Gravação de áudio de Idalina, 1. . ciclo, junho de 2016).

Irene, do $1 .^{\circ}$ ciclo, ressalta que o trabalho de elaboração de tarefas para a aula de investigação se caracterizou por um intenso trabalho em equipe, em que cada um cooperou, cada um fez a sua parte, em que tudo foi negociado e, portanto, foi um aspecto marcante no estudo de aula: 
Começamos com uma tarefa e depois fomos falando, fomos discutindo, fomos modificando e fomos mudando. Fomos modificando, fomos mudando, fomos sempre mudando, adaptando. Um processo de evolução. Foi sempre havendo uma evolução, fomos discutindo o esboço inicial e fomos melhorando [as tarefas] (Gravação de áudio de Irene, 1. ${ }^{\circ}$ ciclo, junho de 2016).

O trabalho cooperativo, que marcou as sessões de planejamento da aula de investigação, para além de fortalecer a interação e a comunicação entre as professoras, propiciou-lhes elaborar as tarefas de uma maneira dinâmica, dialogada e colaborativa, o que as levou a produzir tarefas de melhor qualidade. Marta também destaca o fortalecimento da comunicação no grupo e acrescenta que a cooperação que havia era voluntária e equilibrada:

Nunca teve alguém que se calhar fez mais, que se fez mais presente, que fazia mais fora das sessões e se envolvia menos nas sessões. Não houve nada disso. A nossa comunicação sempre foi muito boa e conseguimos nos comunicar umas com as outras. E nos comunicamos sempre que tínhamos que nos comunicar, é, usando principalmente o aparelho de telemóvel ou por email (Gravação de áudio de Marta, 1. ${ }^{\circ}$ ciclo, junho de 2016).

Portanto, o envolvimento, voluntário e intenso, do grupo no processo fortaleceu a comunicação entre as pares, de maneira que a cooperação que houve na realização atividades foi equilibrada e adequada aos espaços e tempos de cada um. Havia a possibilidade de complementação ou continuação das atividades desenvolvidas nas sessões do estudo de aula em outros momentos, para além das interações presenciais, assim como não havia hierarquias ou imposições.

Luísa, do 2. ${ }^{\circ}$ ciclo, destaca que a cooperação docente precisa ser mais valorizada na prática profissional, pois há na escola uma tendência do professor fechar-se em sua prática e de não existir interação, ajuda mútua nas atividades cotidianas. Conclui que o estudo de aula oportunizou-a perceber a importância da cooperação para o próprio crescimento:

Nós temos, eu acho errado isso, o hábito de fechar-se a si em nossa sala de aula. De não conversarmos e não pensarmos na aula. Não abrimos nossa aula para nossos colegas [...]. [E o estudo de aula] nos ajudou a ver que é preciso nos abrir, ajudar uns aos outros. Porque quando ensinamos costumamos sempre fazer tudo sozinhos (Gravação de áudio de Luísa, $2{ }^{\circ}$ ciclo, junho de 2016).

Além disso, Luísa acrescentou que o estudo de aula, devido às suas especificidades e dinâmica de desenvolvimento em relação a outras experiências formativas que vivenciou anteriormente, favoreceu a aproximação entre os pares e o fortalecimento do trabalho em grupo, que era realizado de forma mais intensa e colaborativa:

No estudo d'aula foi tudo diferente, foi mais intenso [...] ajudamo-nos mais [...]. E o grupo trabalhou junto para que chegássemos lá. [...]. Nós éramos um grupo coeso. [Outra] coisa desta formação, daquele estudo d'aula, que marcou foi a maneira como nós fazíamos as coisas, como elaborámos elaboramos as tarefas para levar para a sala de aula, pronto. Tudo era feito de uma forma mais, fazíamos tudo em grupo (Gravação de áudio de Luísa, 2. ${ }^{\circ}$ ciclo, junho de 2016). 
O grupo de professores do $3 .^{\circ}$ ciclo destacou, principalmente, a possibilidade de consolidarem o trabalho em equipe, isto é, trabalhar cooperativamente e em conjunto, prática esta que, devido à predominância da cultura do individualismo na escola, não faz parte das vivências da rotina do professor:

Eu acho que o grupo de colegas que tínhamos, [...] era um grupo que funcionava. Nós nos dávamos muito bem, portanto. Eu acho que o trabalho colaborativo entre nós correu muito bem, pronto. Porque, às vezes, nem sempre é assim, não é. O fato de as pessoas se darem bem fora da formação. Também éramos amigos e colegas. E penso que o estudo de aula me fez perceber a importância desse trabalho colaborativo entre os professores (Gravação de áudio de Alda, 3. ${ }^{\circ}$ ciclo, julho de 2016).

Destacam, ainda, o acompanhamento intenso por parte dos formadores que marcou o processo, configurando uma forma de cooperação entre professores participantes e formadores e, portanto, agregando valor às vivências do grupo no estudo de aula. Portanto, a cooperação que se estabeleceu foi permeada por outros elementos, como a negociação dialogada de todo o processo que envolveu os estudo de aula e a igualdade de papéis, marcando a experiência vivenciada por estes professores.

Pois, foi um bocado isso, percebi logo no início que a abordagem dessa formação foi um pouco diferente, porque teve um acompanhamento muito intenso por parte dos formadores, então houve acompanhamento intenso e entre nós também havia cooperação. Fazíamos as coisas da formação sempre em grupo e todos ajudavam, cada um fazia um pouco. [Além disso, neste processo] o grupo comunicou-se mais (Gravação de áudio de Idália, 3. ciclo, junho de 2016).

Outro aspecto destacado também por Idália refere-se à intensificação da comunicação no grupo, que favoreceu a socialização de experiências e propiciou o engajamento de todos na elaboração das atividades do estudo de aula. Para além, apontam que a cooperação que houve no grupo foi marcada pelo bom relacionamento que havia entre eles, conforme assinala José:

Acho que as pessoas do grupo, eu acho que todo o grupo participou. Não houve algo assim, não lembro de ter alguém que fizesse mais, ou menos, alguém que se comunicava mais na escola. Tínhamos um bom relacionamento. E nós que estávamos em outra escola, por causa da distância, muitas vezes fazíamos as coisas, pesquisávamos as coisas e mandávamos por email. Mas, sim, houve envolvimento de todos. Portanto, dava-se uma ideia de depois cada um, por acaso, fazia aquilo que podia. Cada um estava a perceber se tinha mais tempo, ajudava o outro. E [...] foi positivo. Foi um grupo que funcionou bem. [...] E também com o trabalho nas escolas fica mais fácil para pesquisar, por causa do tempo. E na formação conseguimos fazer estas coisas, porque trabalhamos em equipa (Gravação de áudio de José, 3. . ciclo, junho de 2016).

Portanto, para os professores do $3 .^{\circ}$ ciclo, a partir das formas de comunicação que praticavam no grupo, puderam organizar e desenvolver as atividades do estudo de aula e as atribuições profissionais de acordo com as condições e possibilidades de cada um. Ou seja, cada professor, segundo seu ritmo próprio de trabalho, cumpria suas atribuições nas etapas do estudo de aula, adequando-as convenientemente ao seu tempo e as suas condições de trabalho. Além destes aspectos, José acrescenta que o processo de elaboração de tarefas para a aula de 
investigação envolveu a todos de forma intensa e dialogada. Destacou que "A partir de uma tarefa fomos acrescentando. Alguém diz faz isso, acrescenta aquilo e fomos melhorando. Foi um processo mesmo, que foi evoluindo" (Gravação de áudio de José, 3. ${ }^{\circ}$ ciclo, junho de 2016). E este processo permitiu-lhes melhorar crescentemente as tarefas matemáticas que seriam propostas aos alunos na aula de investigação.

Complementando, Idália chama a atenção para os impactos das mudanças políticoeducacionais no cotidiano das escolas, as quais pressionam o professor a adotar rotinas de trabalho individualizadas, e assinala que o estudo de aula lhes permitiu experimentar uma forma diferente de realizar tais atividades, em que a cooperação concretizou-se no coletivo, permeado pelo diálogo:

As mudanças [...] implementadas a cada mudança de governo atropelam o professor. E deixamos de trabalhar em equipa, de conversarmos e de fazer o planeamento com a ajuda, com o apoio dos colegas. Acabamos por nos isolar e a fazer as coisas sem pensar (Gravação de áudio de Idália, $3 .^{\circ}$ ciclo, junho de 2016).

Portanto, para os professores do $3 .^{\circ}$ ciclo, o estudo de aula permitiu, principalmente, vivenciar uma forma de cooperação profissional totalmente diferente. Mediante este nível de cooperação e coletividade, os professores realizaram o planejamento da aula de investigação seguido da sua lecionação e, paralelamente, desenvolveram as demais atividades profissionais de modo intenso, dialogado e colaborativo, modificando, assim, as relações pessoais e algumas rotinas profissionais.

Em síntese, o estudo de aula propiciou experiências profissionais em que a coletividade, a cooperação, a negociação, a confiança e o diálogo predominavam. O bom relacionamento que havia entre os professores favoreceu a comunicação e o envolvimento de todos nas atividades do estudo de aula, de modo que sempre buscavam cooperar voluntariamente com os colegas que tinham menos tempo. E, portanto, o processo que envolveu o estudo de aula propiciou aos professores de todos os ciclos vivenciarem situações profissionais e formativas de natureza muito diferente do habitual individualismo. $\mathrm{E}$ tais aspectos contribuíram para o desenvolvimento profissional do grupo.

\subsection{Apoio e incentivo pessoal}

Para as professoras do $1 .^{\circ}$ ciclo, o estudo de aula envolveu-as de uma forma que se sentiram fortalecidas para enfrentar os desafios que chegaram com a implementação do novo programa de Matemática. Destacam, especialmente, o respeito, o clima de confiança e incentivo pessoal que se estabeleceu no grupo, que favoreceu o envolvimento nas atividades do estudo 
de aula e as motivou a envolver-se intensamente no processo:

Penso que uma das coisas que havia naquela formação, uma coisa que havia entre nós, no nosso grupo do 1. ${ }^{\circ}$ ciclo, era a confiança, o apoio entre nós. Sempre nos incentivámos umas às outras. E o trabalho em grupo foi também intenso e, portanto, os encontros da formação eram imenso construtivos, imenso positivos (Gravação de áudio de Idalina, $\mathbf{1 .}^{0}$ ciclo).

Irene, particularmente, pontua a confiança e o incentivo que havia no grupo, que contribuiu para que o trabalho fosse realizado de modo colaborativo, no qual as tarefas eram distribuídas e cada um realizava uma parte, sem que houvesse constrangimento a alguém. $\mathrm{Ou}$ seja, havia um envolvimento voluntário de cada professor nas atividades do estudo de aula, de modo que não havia espaço para qualquer mal-estar, pois as hierarquias foram superadas.

O envolvimento [do grupo] foi bom, foi dentro daquilo que se tinha de esperar. Não teve qualquer vergonha. Fomos combinando o trabalho, temos de fazer isso, temos de combinar aquilo. Tudo foi dentro do normal. Não houve constrangimentos, nenhum desconforto (Gravação de áudio de Irene, 1. ${ }^{\circ}$ ciclo, junho de 2016).

Marta, por seu lado, acrescenta que o ambiente de confiança e o incentivo que se estabeleceu ao longo do estudo de aula contribuiu para que ela pudesse superar algumas inseguranças pessoais, assim como envolveu a outras pessoas não diretamente ligadas ao trabalho de sala de aula.

Eu acho que esta formação [o estudo de aula] envolveu-nos a todos e, portanto, envolveu a mim, envolveu aos meus alunos, envolveu aos pais, aos colegas. E com esse envolvimento, se calhar, também aprendemos sobre questões, sobre a parte dos conhecimentos, sobre como transmitimos conhecimentos e essa parte dos conhecimentos é mesmo muito importante, pois se não compreendemos muito bem uma certa coisa, essa coisa não corre tão bem. E, portanto, eu estar segura em questões é muito importante [...] E essa segurança para trabalhar esse tópico em sala de aula eu consegui lá na formação (Gravação de áudio de Marta, 1. ciclo, junho de 2016).

Acrescenta, ainda, que, embora inicialmente tenha se sentido apreensiva com a formação, porque focava a Matemática, que é uma área que tinha alguma dificuldade na infância, ela "sabia que havia também a possibilidade de aprender algo da Matemática. [...] E, portanto, o processo foi se dando aos poucos " (Gravação de áudio de Marta, 1. ' ciclo, junho de 2016), de modo que ela foi envolvendo-se e o "receio transformou-se em confiança" (Gravação de áudio de Marta, 1. ${ }^{\circ}$ ciclo, junho de 2016).

Relativamente a este aspecto (apoio e incentivo pessoal), Luísa, do $2 .^{\circ}$ ciclo, acrescentou que o apoio que havia entre eles favoreceu-lhe superar algumas de suas inseguranças pessoais e profissionais, especialmente sobre ter alguém a assistir a sua aula:

Pois. Eu, àquela altura, tinha muito medo disso, porque sou uma pessoa assim, que não tem muita segurança. E dar aquela aula não era uma coisa fácil para mim. Sempre havia o medo de que as pessoas iam ser avaliadas ali [...]. E tinha uma coisa assim nesse aspeto, e depois ok. Eu podia dizer qualquer coisa para quem estava a ver a minha aula, e pronto. Eu consegui desmistificar isso, de ter alguém a ver minha aula. [E isto foi possivel devido ao] clima de 
confiança que estabelecemos entre nós [...] E sou muito grata aos formadores. Agradeço imenso a eles (Gravação de áudio de Luísa, 2. ${ }^{\circ}$ ciclo, junho de 2016).

O grupo de professores do $3 .^{\circ}$ ciclo destacou aspectos relacionados à confiança, à parceria entre os professores, também por parte dos formadores, que contribuíram para que as atividades fluíssem bem. Alda ressalta que o estudo de aula foi uma forma diferente de realizar as atividades profissionais, "diferente daquela que fazemos sozinhos, individualmente, porque somos nós que preparamos tudo, não é, fazemos o processo todo sozinhos: o objetivo, o planejamento, as tarefas” (Gravação de áudio de Alda, 3. ${ }^{\circ}$ ciclo, julho de 2016).

Por seu lado, Idália aponta que o estudo de aula "foi uma forma diferente de fazer isso, com muitas pessoas a procurar, muita gente a pensar sobre todas as coisas, portanto, $e$ bastante, também, dirigida, muito acompanhada, em que havia mais probabilidade, mais possibilidades de sucesso" (Gravação de áudio de Idália, 3. ciclo, junho de 2016). E concluem que o bom desenvolvimento das atividades profissionais do professor e, especialmente, a concretização da colaboração docente pressupõe envolvimento e motivação dos professores.

Sobre isso, Marta assinala que "A motivação também é importante, e que veio delas [referindo-se as colegas]. Sem motivação não há envolvimento" (Gravação de áudio de Marta, 1. ${ }^{\circ}$ ciclo, junho de 2016). Deste modo, a experiência formativa no estudo de aula promoveu a confiança e a motivação do grupo, que lhes oportunizou envolver-se no planejamento profissional e com o ensino da Matemática em sala de aula, favorecendo assim o crescimento do grupo.

Por fim, ao refletir sobre o estudo de aula, em sua totalidade, Marta destaca que as formas de partilha, diálogo, cooperação e incentivo que puderam experimentar por meio desta abordagem, transportaram-se para a dimensão da vida pessoal, permitindo-lhe trabalhar de uma outra maneira e perceber os desafios cotidianos de uma forma diferente, mais reflexiva:

E depois há coisas que profissionalmente se transportam para nossa vida pessoal, não é, que nos fazem pensar nossa vida pessoal, e há coisas que começamos fazer diferente. E lá partilhávamos tudo. E a partilha com os colegas é muito importante, a partilha. E este grupo tem isso em sua ação, muita partilha, não se esconde nada, um texto que temos, um texto que lhes apresentamos, e isso é sempre bom. E isso é conseguir essa ascensão profissional [...]. É um projeto muito ambicioso, e que criou-nos a expectativa logo no início. Quando o projeto começou percebemos isso. E o mérito foi todo das formadoras, que estavam ali e que propiciaram isso, que perceberam essa capacidade em nós (Gravação de áudio de Marta, $1 .^{\circ}$ ciclo, junho de 2016).

Portanto, as vivências dos professores nos estudos de aula oportunizaram-lhes situações profissionais em que a partilha, a cooperação e o apoio pessoal, elementos intrínsecos à concretização da colaboração profissional docente, propiciaram-lhes experimentar dinâmicas de planejamento e organização profissional que superaram o individualismo e contribuíram 
para a sua confiança e satisfação profissional, consolidaram a interação e o diálogo entre eles, permitiram outras formas de organização coletiva, favorecendo, assim, o desenvolvimento profissional desses professores.

\section{Discussão dos aspectos evidenciados}

No âmbito dos estudos de aula em que os professores participantes envolveram-se, a partilha concretizou-se em face aos hábitos de trabalho daqueles grupos profissionais, nos objetivos almejados mediante suas práticas, nos modos de agir desenvolvidos nas interações com os pares e nas práticas profissionais cotidianas (HARGREAVES, 1998; SECO, 2009), no enfrentamento dos desafios da profissão, evidenciando um dos aspectos da cultura docente naquele contexto, constituída como elemento identificativo e caracterizador daquela organização (agrupamento) escolar (SECO, 2009).

A análise dos depoimentos evidencia que os estudos de aula oportunizaram aos professores desenvolverem trabalho de cunho colaborativo, caracterizado pela partilha de objetivos de ensino e materiais didáticos, preocupações profissionais, discussão de ideias e desenvolvimento conjunto de recursos de ensino (BURROUGHS; LUEBECK, 2010; MURATA, 2011; PUCHNER; TAYLOR, 2006), negociação de ideias e propostas de intervenção naquela realidade.

Os professores evidenciaram que esta abordagem de formação propiciou diferentes níveis de partilha, tais como a partilha de materiais de ensino e recursos didáticos, objetivos de ensino, angústias e inseguranças e, especialmente, os desafios advindos desta abordagem de desenvolvimento profissional. Partilhavam angústias relativas às dificuldades de aprendizagem matemática dos alunos, aos desafios que se impunham com a introdução de um novo programa curricular de Matemática, aos objetivos e desafios relacionados ao ensino que teriam de promover em sala de aula, assim como partilhavam impressões sobre a concretização do ensino de tópicos da Matemática com os alunos. Estas vivências contribuíram de maneira significativa para a consolidação da colaboração profissional, tanto no processo de planejamento e concretização da aula de investigação, quanto na organização de outras atividades cotidianas, agregando, portanto, outros valores às práticas cotidianas daquela cultura profissional.

Portanto, assumindo que a colaboração profissional se consolida quando elementos contraditórios, favoráveis e desfavoráveis, são partilhados e discutidos em um contexto em que se procura o apoio necessário para aprender (BORGES, 2007; PONTE, 2014), constatamos que, no estudo de aula, os processos de partilha vivenciados pelos professores os mobilizaram 
a se envolverem de maneira diferenciada no seu desenvolvimento profissional. Este envolvimento, mais intenso e reflexivo, contribuiu para que os professores manifestassem maior disponibilidade para experimentar uma nova prática, nomeadamente a aula de investigação, que lhes permitiu promover a abordagem exploratória do tópico Números Racionais em sala de aula. Esta experiência, por sua vez, levou-os a aprofundar os conhecimentos sobre este tópico da Matemática e sobre modos de ensiná-lo, mobilizando, assim, novas aprendizagens profissionais, que traduziram-se em uma aula diferente.

Além disso, no estudo de aula, tal como os próprios professores indicam, puderam trabalhar de forma cooperativa, à medida que assumiram conjuntamente a elaboração de tarefas exploratórias de Matemática para a aula de investigação (BOAVIDA; PONTE, 2002; PONTE et al., 2014), buscando antecipar os desafios que o tópico dos números racionais poderia trazer para os alunos, assim como ouvindo as experiências e impressões dos colegas sobre o ensino deste conteúdo em sala de aula.

Deste modo, o trabalho em equipe permitiu aos professores desenvolver uma necessidade compartilhada relativa ao ensino em sala de aula, valorizando as contribuições dos colegas (HARGREAVES, 1998; LITTLE, 1990) e trabalhando coletiva e cooperativante para alcançar este propósito (GOULET; AUBICHON, 1997). Na perspectiva dos sete professores, isso permitiu-lhes experimentar uma forma totalmente diferente de planejar uma aula, mediante a qual o individualismo predominante na cultura profissional dos professores deu lugar ao trabalho coletivo, à discussão, à reflexão, ao diálogo e à cooperação.

A dinâmica das culturas profissionais que perpassam as rotinas de professores influencia as suas ações e seus modos de pensar (HARGREAVES, 1998; GUERRA, 2000; BORGES, 2007), de maneira que vivências distintas concretizadas no seio destas culturas podem levá-los a olhar de forma crítica para práticas estabelecidas (FIALHO, SARROEIRA, 2012; PONTE et al., 2012). Este aspecto foi destacado pelos professores, na medida em que confrontaram algumas experiências formativas anteriores com a dinâmica que experimentaram no estudo de aula, na qual trabalharam numa base de igualdade (BOAVIDA; PONTE, 2002) e cordialidade, buscando cooperar com o grupo no sentido de alcançar objetivos em que todos se beneficiaram.

Além disso, destacam que a cooperação que se verificou entre os pares, assim como entre os professores e os formadores, foi diferente, porque, embora as pessoas tivessem assumido estatutos e papeis diferenciados no processo (BOAVIDA; PONTE, 2002), cada qual contribuiu a seu modo, dentro das suas possibilidades, para a elaboração de boas tarefas exploratórias, assim como para a concretização de uma boa aula de investigação. Portanto, a cooperação que houve concretizou-me em torno de um objetivo comum e foi permeada por 
outros elementos, tais como o diálogo, a negociação de ideias e significados e a superação de hierarquias, contribuindo para o desenvolvimento profissional de todos os envolvidos.

Os professores mencionaram, também, que o estudo de aula possibilitou a superação da cultura do individualismo no âmbito da cultura profissional de professores, sobretudo no que diz respeito às ações de planejamento profissional e na continuidade das atividades inerentes à profissão. Ao referirem que o professor tende a isolar-se nas suas rotinas profissionais, evita a discussão e não abre a sua aula para os colegas, revelam que esta forma de cultura profissional precisa ser superada, porque o trabalho colaborativo oportuniza a coletividade e, portanto, seu crescimento e desenvolvimento profissional.

No que diz respeito ao apoio e incentivo pessoal os aspectos marcantes referem-se a confiança que emergiu nas e a partir das interações profissionais com a equipe que participou do estudo de aula, incluindo-se o apoio e acompanhamento intenso da equipe de formadores (DAY, 1999; 2001), que os motivaram a participar e envolver-se fortemente no estudo de aula, assim como dos colegas que os apoiaram a superar alguns desafios que esta abordagem pode trazer às culturas profissionais instituídas. Estes elementos, na perspectiva dos professores, favoreceram o seu crescimento profissional e pessoal, uma das dimensões do desenvolvimento profissional.

Sobre isto, consideramos que a experiência no estudo de aula, no qual sentiram-se apoiados e incentivados, motivou os professores a introduzir mudanças nas estruturas educativas, nas formas de organizar os espaços educacionais e, especialmente, nas relações profissionais concretizadas nestes espaços (HARGREAVES, 1998; GUERRA, 2000), porque viabilizaram o trabalho em equipe, sustentado na partilha e na cooperação, em um ambiente em que encontraram apoio para enfrentar inseguranças e buscar ajuda para os desafios de sala de aula, assim como para fortalecerem a confiança e, portanto, se fortalecerem enquanto coletivo profissional. E esta confiança levou-os a promover uma prática diferente, nomeadamente a abordagem exploratória na aula de investigação, assim como motivou-os a envolver-se de forma intensa nesta abordagem de desenvolvimento profissional, também diferente para eles.

Além disso, no âmbito dos estudos de aula, a colaboração que se registrou entre os professores era voluntária, baseada em um bom relacionamento entre eles (BOAVIDA; PONTE, 2002; PONTE, 2014) e transcendia o tempo e o espaço da formação, isto é, o tempo limitado pelas sessões do estudo de aula. Assim, mediante esta forma de colaboração, os professores participantes puderam fortalecer a confiança, a capacidade de trabalhar em equipe e, desse modo, promover o desenvolvimento profissional docente. Estes aspectos evidenciam que os estudos de aula podem levar os professores a confrontar-se com novas experiências, a 
questionar os obstáculos impostos por certas culturas instituídas, assim como a perceber a necessidade de mudanças nas dinâmicas culturais estabelecidas nas organizações educativas.

Nesta perspectiva, a experiência dos professores participantes nos estudos de aula evidencia a relevância da colaboração para o desenvolvimento profissional docente, colaboração esta que perpassou as dimensões pessoal e profissional, favorecendo algumas aprendizagens profissionais (FULLAN, 1995), modificando as relações e interações entre os professores e, sobretudo, agregando novos elementos àquela cultura profissional, à medida que puderam experimentar situações em que superaram o individualismo, os estatutos de papéis assumidos pelos diversos atores do processo e o isolamento predominante na profissão. Além disso, a colaboração que houve prolongou-se para algumas atividades profissionais cotidianas, especialmente sobre a gestão das rotinas escolares em face aos desafios impostos pelo novo programa.

Portanto, a colaboração que houve nos estudos de aula oportunizou algumas aprendizagens profissionais mediante a modificação de ideias e a reinterpretação de experiências e práticas (DAY, 2001), negociação de significados e práticas profisssionais. E isto foi possível em face da partilha, da cooperação e do apoio pessoal que se concretizaram na interação dialogada e reflexiva com os colegas, promovendo a colaboração e, portanto, o desenvolvimento profissional desses professores.

\section{Considerações finais}

As perspectivas de colaboração profissional concretizadas em um estudo de aula, mediante as reflexões dos professores participantes, prendem-se às especificidades desta abordagem de desenvolvimento profissional docente, particularmente a dinâmica que sustenta a etapa do planejamento da aula de investigação e sua concretização, assim como da etapa de reflexão. Na medida em que os professores puderam experimentar uma forma colaborativa, voluntária e reflexiva de planejamento e concretização desta aula, em que toda a atenção estava voltada para as ações dos alunos e de modo que as impressões e contribuições de cada um tornavam-se fundamentais para as reflexões do grupo, passaram a valorizar a partilha, a cooperação e o apoio pessoal como formas de promoverem o próprio desenvolvimento profissional. Além disso, passaram a valorizar as contribuições do grupo e nele buscar apoio para enfrentar os desafios que se impunham à prática, de forma que o individualismo predominante nas práticas de professores deu lugar à colegialidade e, portanto, à colaboração.

Para além disso, a dinâmica de desenvolvimento do estudo de aula levou os professores 
a transcender a interação profissional que se limita ao espaço e tempo da escola, uma vez que passaram a interagir e a partilhar ideias, angústias, objetivos profissionais e recursos usando outros modos e recursos de comunicação, especialmente e-mail e telemóvel, transcendendo, portanto, o espaço e o tempo das sessões do estudo de aula, que coincidiam com os espaços e tempos das escolas.

Assim, concretizaram o trabalho colaborativo num nível diferente, cujas marcas prendem-se ao diálogo, à comunicação, à reflexão, à flexibilização do tempo e espaço de realização das atribuições profissionais e do estudo de aula e, especialmente, à confiança. E estes aspectos, em seu conjunto, mobilizaram-nos no seu processo de desenvolvimento profissional.

Portanto, as distintas experiências formativas vivenciadas pelos professores em estudos de aula criaram oportunidades de experimentar formas colaborativas distintas de desenvolver as atividades e aprendizagens profissionais, levando-os a questionar os limites impostos pelo individualismo ao seu desenvolvimento profissional. As discussões sobre as possibilidades de concretização da colaboração profissional estudos de aula afiguram-se assim pertinentes, pelo que ressaltamos a necessidade de mais estudos sobre este tema.

\section{Agradecimentos}

Agradecemos, em especial, aos sete professores que participaram deste estudo, concedendo-nos as entrevistas.

\section{Referências}

BARDIN, L. Análise de conteúdo. Lisboa: Edições 70, 1977.

BOAVIDA, A. M.; PONTE, J. P. Investigação colaborativa: potencialidades e problemas. In: GTI (Org.). Reflectir e investigar sobre a prática profissional. Lisboa: APM, 2002. p. 43-55.

BORGES, M. Professores: imagens e auto-imagens. 2007. 670 f. Tese (Doutorado em Educação) Instituto de Educação, Universidade de Lisboa, 2007.

BORKO, H.; PUTNAM, R. Expanding a teacher's knowledge base: A cognitive psychological perspective on professional development. In: GUSKEY, T. R.; HUBERMANN, M. (Ed.). Professional development in education: New paradigms and practices. New York, NY: Teacher College Press, 1995. p. 35-66.

BURROUGHS, E.; LUEBECK, J. Pre-service teachers in mathematics lesson study. The Montana Mathematics Enthusiast, Montana, v. 7, n. 2-3, p. 391-400, 2010.

DAY, C. Desenvolvimento profissional de professores: os desafios da aprendizagem permanente. Porto: Porto, 2001. 
DAY, C. Developing teachers: The challenges of lifelong learning. London: Falmer, 1999.

ERICKSON, F. Qualitative methods in research on teaching. In: WITTROCK, M. C. (Ed.). Handbook of research on teaching. New York, NY: Macmillan, 1986. p.119-161.

FIALHO, I.; SARROEIRA, L. Cultura profissional dos professores numa escola em mudança.

Educação: Temas e problemas, Évora, n. 9, p.1-20, 2012. Disponível em:

$<$ http://dspace.uevora.pt/rdpc/handle/10174/8187>. Acessado em: 20.mar.2017.

FLORES, M. A. The Early years of teaching: issues of learning, development and change. Porto: RÉS, 2004.

FRIESEN, D. The meaning of collaboration: Redefining pedagogical relationships in students teaching. In: CHRISTIANSEN, H.; GOULET, L.; KRENTZ, C.; MAEERS, M. (Org.). Recreating relationships: Collaboration and educational reform. New York, NY: State University of New York Press, 1997. p. 219-231.

FUJII, T. Designing and adapting tasks in lesson planning: A critical process of lesson study. ZDM Mathematics Education, Berlin, v. 48, p. 411-423, 2016.

FULLAN, M. The limits and the potential of professional development. In: GUSKEY, T. R; HUBERMANN, M. (Ed.). Professional development in education: new paradigms and practices. New York, NY: Teachers College Press, 1995. p. 253-268.

GOULET, L.; AUBICHON, B. Learning collaboration: Research in a First Nations teacher education program. In: CHRISTIANSEN, H.; GOULET, L.; KRENTZ, C.; MAEERS, M. (Org.). Recreating relationships: Collaboration and educational reform. New York, NY: State University of New York Press, 1997. p.115-127.

GUERRA, M. A escola que aprende. Porto: Asa, 2000.

HARGREAVES, A. Professores em tempo de mudança: O trabalho e a cultura dos professores na idade pós-moderna. Alfragide: McGraw-Hill, 1998.

HARGREAVES, A. Changing teachers, changing times: Teachers' work and culture in the postmodern age. London: Cassell, 1994.

HARGREAVES, A. Individualism and individuality: Reinterpreting the teacher culture. In: LITTLE, J.W.; MCLAUGHLIN, M. W. (Ed.). Teachers' work. Individuals, colleagues, and contexts. New York-London: Teachers College Press, 1993. p. 51-76.

HUANG, R.; LI, Y.; ZHANG, J.; Li, X. Developing teachers' expertise in teaching through exemplary lesson development and collaboration. ZDM Mathematics Education, Berlin, v. 43, n. 6-7, p. 805$817,2011$.

ISODA, M.; STEPHENS, M.; OHARA Y.; MIYAKAWA, T. (Ed.). Japanese lesson study in mathematics: Its impact, diversity and potential for educational improvement. Singapore: World Scientific, 2007.

LEWIS, C. Lesson study: A handbook of teacher-led instructional change. Philadelphia, PA: Research for Better Schools, 2002.

LEWIS, C. C.; PERRY, R.; HURD, J. Improving mathematic instruction through lesson study: A theoretical model and North American case. Journal of Mathematics Teacher Education, Springer Netherlands, v. 12, p. 285-304, 2009. 
LIMA, J. A. As culturas colaborativas nas escolas. Porto: Porto Editora, 2003.

LITTLE, J.W. Teachers as colleagues. In: LIEBERMAN, A. (Ed.). Schools as collaborative cultures: Creating the future now. New York: Falmer, 1990. p. 165-193.

MURATA, A. Introduction: Conceptual overview of lesson study. In: HART, L.; ALSTON, A.; MURATA, A. (Ed.). Lesson study research and practice in mathematics education. Dordrecht: Springer, 2011.p. 01-12.

OLSON, M. Collaboration: An epistemological shift. In: CHRISTIANSEN, H.; GOULET, L.; KRENTZ, C.; MAEERS, M. (Org.). Recreating relationships: Collaboration and educational reform. New York, NY: State University of New York Press, 1997. p.13-25.

OLSON, J.; WHITE, P.; SPARROW, L. Influence of lesson study on teachers' mathematics pedagogy. In: HART, L.; ALSTON, A.; MURATA, A. (Ed.). Lesson study research and practice in mathematics education. Dordrecht: Springer, 2011. p. 39-58.

PERRY, R.; LEWIS, C. What is successful adaptation of lesson study in the US? Journal Educational Change, Netherlands, v. 10, p. 365-391, 2009.

PONTE, J.P. Da formação ao desenvolvimento profissional. In: APM (Ed.). Actas do ProfMat 98. Lisboa: APM, 1998, p.27-44.

PONTE, J. P. Formação dos professores de Matemática: Perspetivas atuais. In: PONTE, J.P. (Ed.). Práticas profissionais dos professores de matemática. Lisboa: Instituto de Educação da Universidade de Lisboa, 2014. p. 343-360.

PONTE, J. P.; BAPTISTA, M.; VELEZ, I.; COSTA, E. Aprendizagens profissionais dos professores através dos estudos de aula. Perspectivas da Educação Matemática, Campo Grande, n.5, p. 7-24, 2012. (Número Temático).

PONTE, J.P.; QUARESMA, M.; MATA-PEREIRA, J.; BAPTISTA, M. Estudos de aula para promover o desenvolvimento profissional do professor. In: LOSS, A.; CAETANO, A.P.; PONTE, J.P. (Eds.). Formação de professores no Brasil e em Portugal: Pesquisas, debates e práticas. Curitiba: Appris, 2015. p. 227-250

PONTE, J.P.; QUARESMA, M.; MATA-PEREIRA, J.; BAPTISTA, M. O estudo de aula como processo de desenvolvimento profissional de professores de matemática. Bolema-Boletim de Educação Matemática, Rio Claro, v. 30, n. 56, p. 868-891, 2016.

PONTE, J.P.; QUARESMA, M.; BAPTISTA, M.; MATA-PEREIRA, J. Os estudos de aula como processo colaborativo e reflexivo de desenvolvimento profissional. In: SOUSA, J.; CEVALLOS, I. (Eds.). A formação, os saberes e os desafios do professor que ensina Matemática. Curitiba: Editora CRV, 2014. p. 61-82

PUCHNER, L. D.; TAYLOR, A. R. Lesson study, collaboration and teacher efficacy: Stories from two school-based math lesson study groups. Teaching and Teacher Education, Amsterdã (Elsevier), v. 22, p. 922-934, 2006.

ROLDÃO, M. C. Formação de professores e desenvolvimento profissional. Revista Educação, Campinas, v. 22, n. 2, p. 191-202, maio/ago., 2017.

SECO, V. M. M. Cultura de escola e culturas profissionais docentes. 2009. 184 f. Dissertação (Mestrado em Educação) - Instituto Superior de Educação e Trabalho do Porto, 2009. 
SMYTH, J. Teachers's work and labor process of teaching; central problematics in professional development. In: GUSKEY, T.R.; HUBERMAN, M. (Ed.). Professional Development in Education: New paradigms and practices. New York, NY: Teachers College Press, 1995. p.69-91.

STIGLER, J. W.; HIEBERT, J. Lesson study, improvement, and the importing cultural routines. ZDM Mathematics Education, Berlin, v. 48, n. 4, p. 581-587, 2016.

TAKAHASHI, A.; MCDOUGAL, T. Collaborative lesson research: maximizing the impact of lesson study. ZDM Mathematics Education, Berlin, v. 48, n. 4, p. 513-526, 2016.

TEIXEIRA, M. O professor e a escola: Perspectivas organizacionais. Lisboa: McGraw Hill, 1995.

Submetido em 04 de Julho de 2018. Aprovado em 06 de Dezembro de 2019. 